\title{
Dealing with parental concerns: A study of GPs' practice
}

\author{
Caroline Dorothea Poulsen*1, Philip Wilson ${ }^{1,2}$ Anette Hauskov Graungaard ${ }^{1}$, Gritt Overbeck ${ }^{1}$ \\ ${ }^{1}$ The Research Unit for General Practice and Section of General Practice, Department of Public Health, \\ University of Copenhagen, Denmark \\ ${ }^{2}$ Centre for Rural Health, University of Aberdeen, Scotland \\ *Corresponding author at: The Research Unit for General Practice and Section of General Practice, \\ Department of Public Health, University of Copenhagen, Øster Farimagsgade 5, 1014 København K, \\ Denmark. E-mail address: caroline.poulsen@sund.ku.dk (C. Poulsen)
}

\begin{abstract}
Objective: To investigate patterns of GPs' exploration and termination of dialogues about parental concerns in preventive child health assessments.

Methods: Interactional microanalysis of video recordings of 32 preventive child health assessments using conversation analysis.

Results: The GPs asked parents about concerns, but most concerns disclosed by parents were still left unexplored at the end of the consultation. Termination of dialogues about concerns could be achieved effectively by GPs through letting the biomedical agenda dominate or addressing the child directly. The parents generally cooperated with the various approaches to handling concerns.

Conclusion: GPs displayed initial attentiveness towards emotional concerns but did not always follow through with subsequent exploration; many concerns raised were left unexplored. However, the same GP could employ both non-exploratory and exploratory practice within individual consultations. Practice implications: Preventive child heath assessments offer an opportunity for parents to raise concerns about their children's development. Improved understanding of the conversational mechanisms through which concerns are examined or sidelined could allow clinicians to maximise the effectiveness of their preventive consultations.
\end{abstract}

Keywords: child health services; preventive health services; parent-provider communication; conversation analysis; psychosocial well-being

\section{Introduction}

The structure and delivery of preventive child health assessments (CHA) varies internationally [1]. In Denmark, both general practice and community nurses deliver components of the preventive child health programme [2]. The preventive CHAs taking place in general practice consist of three examinations during the first year of life, and one annually until the age of five. The attendance rate in these consultations is high [3] so they provide a valuable opportunity to assess child and family wellbeing. The National Board of Health's recommendations on the preventive CHA suggest that the GP's assessment of the child's psychological and social functioning largely relies on dialogue with the parent [2]. Little is known about the nature of these dialogues. 
Concerns raised by parents have proven to be a potential key to an improved assessment of psychosocial problems and detection of developmental disorder [4-7]. One study of well-child visits reported that about half of parents with children aged 1-12 years had concerns in at least one domain [8]. Although concerns are often present, they are not always discussed in the consultation [8-11]. Barriers such as time limitation, parental embarrassment, feeling uncomfortable or finding it inappropriate to discuss psychosocial issues may explain some of the discrepancy between the presence of concerns and their exploration in the consultation $[9,12]$. To increase the elicitation of concerns about children's psychosocial functioning, interventions such as check-lists, information-giving videos and prompts for parents to ask questions have been designed [13-16]. Although these tools can ensure that concerns are touched upon, they do not necessarily influence what happens after the concern has been raised. To our knowledge, only a few studies have investigated how physicians respond to concerns in paediatric settings $[17,18]$. These studies show that the physician's response, the topic of the concern and parental openness may all determine the extent of parental disclosure $[17,18]$. The interaction between health visitors and first-time mothers has also been studied [19]. Although concerns were not the main focus, the authors provided some fundamental knowledge on institutional talk in how 'and-prefaced' questions can mark routine activities whereas non-and-prefaced questions can mark departure from the routine activity. This knowledge creates an interesting starting point for research into concerns, as they are sometimes brought up during routine activity and the GP has to decide whether to proceed with his/her agenda or make a departure and attend to the concern. The present study aimed to investigate the patterns of GPs' exploration and termination of dialogues about concerns with a view to contributing further knowledge about a potentially modifiable aspect of management of concerns in the consultation, namely the clinician's conversational approach.

\section{Methods}

The present paper arose from a feasibility study taking place in 2017 and 2018 . The feasibility study aimed to assess if it was possible to increase GPs' focus on parent-child-interaction in the preventive CHA in general practice. GPs were asked to video-record their preventive CHAs and this resulted in 32 video recordings (mean duration 26 minutes $^{1}$ ). Watching the videos, we observed that GPs dealt with parental concerns in different ways and dialogues about these concerns therefore became the analytical focus.

\subsection{Participants}

Ten GPs (eight females) were invited to participate in the study. The GPs represented eight different clinics in urban, suburban and rural locations. The age range was 33-67 years (mean 47). Years of experience ranged from none (in training) to 20 years (mean eight years).

The GPs were given a structured child medical record that enhanced a systematic collection of information on psychosocial topics. Furthermore, all parents were asked to complete a Hospital Anxiety and Depression Scale questionnaire (HADS) [20] and for parents of children aged five months

\footnotetext{
${ }^{1}$ The mean duration was longer than the average mean duration of preventive CHA [38] as the GPs spent extra time introducing a web-based programme used in the feasibility study.
} 
to two years an Early Symptomatic Syndromes Eliciting Neurodevelopmental Clinical Examinationsquestionnaire (ESSENCE-Q) [21] and bring them to the consultation.

The GPs recruited 32 children representing the age range of five weeks to two years. Of the children, 15 were boys and 17 were girls. In 22 of the assessments only the mother participated, in one only the father, in seven both parents were present and in two the mother was accompanied by her sister or son. All parents gave informed consent. In Denmark, the National Committee on Health Research Ethics only assesses the ethical acceptability of biomedical research, so it was not possible to obtain formal ethical committee approval.

\subsection{Analysis}

We used conversation analysis (CA) to elucidate the patterns of GPs' responses to parental concerns. CA studies the inherent structural organisation of interaction [22]. By analysing utterances in their sequential context, the means by which the GP and parent collaborate on mutual understanding become apparent: The parent's understanding of the GP's utterance is shown in the parent's response and vice versa. Throughout the sequential analysis, the analyst asks the central question in CA: "Why that now" [23]. Asking why the GP or parent says exactly that at a particular time ensures that the results are validated in the next turn.

Initial thoughts on the video recordings were discussed briefly by $\mathrm{CP}, \mathrm{GO}$ and PW. CP identified extracts from the video recordings where a concern was raised. A concern was defined in accordance with a previous suggested definition where concern related to possible unpleasant or stressful emotions [24]. This definition covered both explicitly expressed concerns (e.g. "I do get a little concerned") and concerns that were mentioned more implicitly (e.g. "it was not what I expected from my first pregnancy", "it was tough"). GO and CP went through all identified concerns and cases in doubt were discussed. For each concern presented, the design of the GPs' preceding turn was categorised as either optimised or non-optimised [25]. It was labelled as optimised when the utterance's grammar and/or content favoured a confirmation of a positive health outcome. The GPs' subsequent turn after the concern was then categorised as either exploratory (e.g. "is it too tough?") or non-exploratory (e.g. affiliating minimal responses or no responses at all). Extracts were transcribed according to Jefferson's convention of CA [26] and CP completed the primary analysis. Subsequently, CP and GO looked for recurrent patterns and discussed these in the research group consisting of $\mathrm{CP}, \mathrm{GO}, \mathrm{PW}$ and $\mathrm{AG}$. The transcriptions are presented in idiomatic English translations. The original Danish transcriptions and an overview of the transcription symbols are presented in the supplementary online appendix.

\section{Results}

\subsection{Variation in exploration of concerns}

We identified 50 concerns in the consultations (ranging from 0 to 6 , mean 1.6 per consultation). The concerns covered a broad spectrum of topics (e.g. feeding, activity level, surgical operations, illness in the family, siblings, relationship and others). Both GPs $(n=44)$ and parents $(n=6)$ initiated dialogues about concern. In 27 cases instruments such as the structured child medical record and questionnaires (HADS and ESSENCE-Q) were used in the consultation. The instruments were used in both optimised and non-optimised designs and did not predict exploration: see Table 1 . The variation in exploration was seen both within and across consultations. 


\begin{tabular}{|lcc|}
\hline & $\begin{array}{c}\text { Optimised design } \\
(\mathrm{n}=10)\end{array}$ & $\begin{array}{c}\text { Non-optimised design } \\
(\mathrm{n}=34)\end{array}$ \\
+ Exploration & 3 & 14 \\
- Exploration & 7 & 20 \\
\hline
\end{tabular}

Table 1: Cross tabulation of design of preceding questions with whether or not further exploration occurred.

\subsubsection{Non-optimised design: Exploration}

In order to explore concerns, the GP has to have some idea about the potential presence of a problem, possibly stimulated by a parent's subtle disclosure. Before extract 1, the GP learns that the mother lives alone with her two children who rarely see their fathers. The GP treats this information as a potential cause for concern and continues the dialogue showing sensitivity to the mother's situation.

\begin{tabular}{|c|c|c|}
\hline & & \\
\hline 1 & GP & e::h but I suppose it can I can imag- understand it is quite tough \\
\hline 2 & $\mathrm{M}$ & .hehe .hyes it is [.hhh] \\
\hline & & ((the mother smiles and laughs)) \\
\hline 3 & GP & {$\left[{ }^{\circ} \mathrm{hehe}^{\circ \circ}\right]$} \\
\hline 4 & GP & yeah? \\
\hline & & ((the mother changes to a serious facial expression)) \\
\hline 5 & $\mathrm{M}$ & yes \\
\hline 6 & GP & is it too tough? $\left[{ }^{\circ} \mathrm{I}\right.$ mean $\left.^{\circ}\right]$ \\
\hline 7 & M & been tough $\quad$ [yes it] I think it is [I mean] I actually think so I mean I it has \\
\hline & & ((the mother is nodding)) \\
\hline 8 & GP & [yes] \\
\hline
\end{tabular}

The GP develops the gist of the mother's earlier statements by expressing support and formulating the mother's feeling and hereby initiates an exploration of a potential concern (line 1) [27]. The mother's confirmation displays some ability to take the trouble lightly as it is accompanied with laughter (line 2) [28]. The overlapping quiet laugh does not align to mother's laugh (line 3) and the GP encourages elaboration with a "yeah?" (line 4) and thereby exhibits "trouble-receptiveness" [28]. The mother changes to a serious facial expression and responds with a minimal confirmation (line 5). The GP orients the mother to the potential presence of problem (trouble-premonitory) [29] now employing the yes/no interrogative "is it too tough?" and the mother productively overlaps and confirms (line 6 and 7). In the subsequent discussion not shown in the extract the mother tells that she sometimes has insufficient sleep, low mood and struggles to nurture her child when under pressure. 


\subsubsection{Non-optimised design: No exploration}

The most frequently occurring local context was a non-optimised question from the GP with no exploration after the concern was presented. In extract 2, the GP and mother are sitting next to each other and the child is sitting on her mother's lab.

Extract 2 (C22)

\begin{tabular}{|c|c|c|}
\hline 1 & GP & and what is it like to get such a little one that changes your life completely? \\
\hline 2 & $\mathrm{M}$ & $\begin{array}{l}\text { that is }(.) \text { something you just get used to } \uparrow \text { hehehe but it is also a good thing hehe } \\
((\text { smiles }))\end{array}$ \\
\hline 3 & GP & .hhh yea::h \\
\hline 4 & $\mathrm{M}$ & $\begin{array}{l}\text { so:: (.) but there is of course a lot of stuff e::h that you have to come to grips with } \\
\text { and: }\end{array}$ \\
\hline 5 & GP & yes \\
\hline 6 & M & yes \\
\hline 7 & GP & now she is the one setting the agenda \\
\hline 8 & M & $\begin{array}{l}\text { yes that's right; for when you can sleep when you can do all sorts of things a:nd } \\
\text { (1.0) you also get a different relationship to body fluids he[hehe of] .hhdifferent } \\
\text { kinds }\end{array}$ \\
\hline 9 & GP & [hehe yes] \\
\hline 10 & GP & $\uparrow$ with everything you bring up ((looking at the child)) \\
\hline 11 & M & yes she's actually sick a lot ((turning her head from the child and towards the GP)) \\
\hline 12 & GP & $\uparrow$ are you such a sicky baby? ((looking at the child)) \\
\hline 13 & $\mathrm{M}$ & ye::s such a real sicky baby ((looking at the child)) \\
\hline 14 & GP & it's just before a smile appears (.) has she begun to smile yet? \\
\hline
\end{tabular}

The GP sets off with an open, non-optimised question orienting towards potential psycho-social overload connected to having a new-born (line 1). Again, the small laugh displays an ability to treat the trouble lightly (line 2) [28]. The GP stimulates a little more concern disclosure about workload and getting enough sleep (line 7 and 8). The mother continues a light humorous approach with "you also get a different relationship to body fluids hehe". The GP aligns the humorous tone and makes an assessment of the amount of vomit (line 10). This creates an opportunity for the mother to confirm and upgrade the assessment "yes she's actually sick a lot" as she turns her head away from the child to the GP (line 11). By this the mother indicates the amount of vomitus might not be normal. The GP does not respond to this as a candidate area for further exploration but terminates the dialogue by continuously looking at and addressing the child in the humorous tone that the mother initiated.

\subsubsection{Optimised design: Exploration}

The GPs sometimes departed from their agenda when a concern was raised during routine questioning. In some of these cases the GP explored the emotional aspects of the concern (see extract 6) and in other cases the GP explored the biomedical aspect of a concern. Extract 3 is placed during a sequence of andprefacing routine questions. 


\begin{tabular}{|c|c|c|}
\hline \multicolumn{3}{|c|}{ Extract $3(C 4)$} \\
\hline 1 & GP & and eh the pregnancy and birth went well? \\
\hline \multirow[t]{2}{*}{2} & M & $\begin{array}{l}\text { hh yes e::h during the pregnancy I had surgery around week } 16 \text { eh because I (.) I } \\
\text { had a cyst in my abdomen }\end{array}$ \\
\hline & & $\begin{array}{l}\text { ((the GP and mother are walking toward the changing table, the GP has her back to } \\
\text { the mother)) }\end{array}$ \\
\hline \multirow[t]{2}{*}{3} & GP & $\uparrow$ oh my gosh (.) [oh] \\
\hline & & ((The mother is putting down the child on the changing table)) \\
\hline 4 & M & [eh] so it was (.) [well] it was a [quite] different- [tough] \\
\hline \multirow[t]{2}{*}{5} & GP & 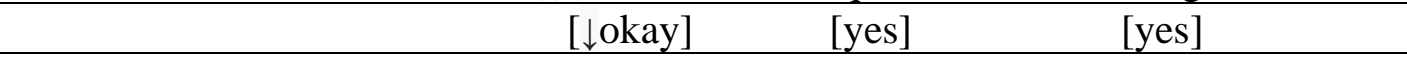 \\
\hline & & ((both the mother and the GP look at child in front of them)) \\
\hline 6 & GP & how was it keyhole surgery? \\
\hline
\end{tabular}

The declarative format and the wording "went well" favours a response embodying a positive health outcome (line 1) [25]. Although the mother confirms, it is done with hesitation and sound prolongation indicating a problem; the mother underwent surgery (line 2). The GP's "oh my gosh (.) oh" marks a change in the GP's knowledge (line 3) [30] and allows the mother to continue as she makes an assessment (line 4) "eh so it was (.) well it was a quite different- tough". The mother does not continue her turn which leaves room for the GP to explore the emotional aspects of her utterance. The GP's contingent question marks a departure from the routine agenda (line 6) [19]. However, the GP misses the opportunity to explore the emotional aspects of the mother's disclosure; instead the contingent question is biomedical. After further discussion of the surgery (29 turns not shown) the GP resumes the agenda with an and-prefaced question about the husband's work.

\subsubsection{Optimised design: No exploration}

Instead of aligning to the optimised question, some parents expressed a concern in the next turn. During some of these dialogues the GP adhered to the orientation towards a healthy child and did not explore the concern any further. In extract 4, the GP asks routine questions about the family network, eating and sleep.

Extract 4 (C3)

\begin{tabular}{|c|c|c|}
\hline 1 & GP & $\begin{array}{l}\text { and he sleeps } \uparrow \text { quite well [ } \uparrow \text { the]re aren’t any problems (.) and his daily rhythm } \\
\uparrow \text { also seems really good }\end{array}$ \\
\hline 2 & $\mathrm{M}$ & {$[$ yes] } \\
\hline 3 & M & $\begin{array}{l}\text { yes I think so I mean I have als- been thinking you know in terms of maybe what } \\
\text { you read if he sleeps (1.0) } \uparrow \text { a bit too much or because he he }\end{array}$ \\
\hline 4 & GP & you know what (.) children are different \\
\hline 5 & M & $\uparrow$ yes \\
\hline 6 & GP & right? \\
\hline
\end{tabular}

In line 1 the GP poses three consecutive declaratives: "and he sleeps quite well there aren't any problems (.) and his daily rhythm also seems really good"; these favour a positive health outcome 
confirmation [25]. The mother's response is initially preferred with the prefacing agreement "yes I think so" followed by a weak disagreement where she expresses concern about the child sleeping too much (line 3) [31]. When the mother starts searching for words, the GP self-selects the next turn and normalises, stating that children are different. The normalisation is enforced with the grammatically interrogative but prosodic declarative "you know what" (line 4). The mother encourages continuation (line 5) and the GP continues by tagging her argument that children are different with "right" and thereby seeks the mother's agreement which she gets in the following turns (line 6).

\subsubsection{From no exploration to exploration}

GPs showed different exploratory attitudes within the same consultation. In the case of no exploration, the GPs could miss a concern while focussing on a narrow topic agenda. However, as extracts 5 and 6 illustrate, exploration could be seen in the same consultation when the GP departed from the narrow topic agenda. The extracts take place after the GP has reviewed the HADS and ESSENCE-Q questionnaires. The GP is sitting at her desk (out of camera view), while the mother is standing by the changing table with her back to the GP.

Extract $5(C 32)$
\begin{tabular}{|l|l|l|}
\hline 1 & GP & $\begin{array}{l}\text { but e::h (.) but e::h (.) there is you know nothing here in this and I can't see } \\
\text { anything you are (1.0) are concerned about (.) in [like] her [daily] life }(.){ }^{\circ} \text { like }{ }_{i}{ }^{\circ}\end{array}$ \\
\hline 2 & M & \multicolumn{1}{c|}{$[$ no] [no] } \\
\hline 3 & M & $\begin{array}{l}((\text { the mother turns around and looks in the direction of the GP while shaking her } \\
\text { head })\end{array}$ \\
\hline & & no:: (.) well no not in relation to her. \\
\hline 4 & GP & no \\
\hline
\end{tabular}

The GP's conclusion that there are no developmental and emotional problems favours a negative confirmation (line 1). The mother's initial confirming overlap is succeeded by a delayed dispreferred response (line 2 and 3). The mother's cue of a potential concern (line 3) objects to the narrow topic agenda set up in the GP's question [32]. This provides the GP with a window to explore other potential concerns, an opportunity the GP does not seize with the confirming "no" (line 4). After 12 turns (not shown) where the GP does not orient to the mother's cue, the mother explicitly expresses that she is concerned about her older daughter's future cleft palate surgery: "So there is (.) it should probably be said that to be completely honest there is a lot (.) we have a lot of concerns in relation to the older one".

Later in the same consultation in extract 6, the GP has departed from the narrow topic agenda and displays sensitivity towards the mother's concern.

Extract $6(C 32)$
\begin{tabular}{|l|l|l|}
\hline 1 & GP & $\begin{array}{l}\text { so: }(.) \text { and is it something you like (.) well of course it is something you worry } \\
\text { about e:h of course [when] she needs surgery }{ }^{\circ} \text { and so } \text { on }^{\circ} \text { is it something that }=\end{array}$ \\
\hline 2 & M & [yes] \\
\hline 3 & GP & $=$ =like affects you at home you think o:r? \\
\hline
\end{tabular}




\begin{tabular}{|l|l|l|}
\hline 4 & M & m:::m yes sometimes \\
\hline 5 & GP & y[es] \\
\hline 6 & M & {$[$ well[:]] } \\
\hline 7 & GP & [so] do you get upset about it or a little e::h; \\
\hline 8 & M & yes I may be worried [because] li:ke it's ju:st it's just a d[d $(0.6) d]$ everything $=$ \\
\hline 9 & GP & [yes] \\
\hline 10 & M & =is relatively of course but it is just a hell of a big operation a: ${ }^{\circ}$ :nd \\
\hline 11 & GP & yes and eh s such a small child right $;$ \\
\hline
\end{tabular}

The GP's response "well of course it is something you worry about e: h of course..." is affiliative (line 1) and followed by a yes/no interrogative that investigates the extent of the concern (line 3 ). After the mother's weak confirmation (line 4), the GP encourages continuation by suggesting an interpretation of the mother's feeling (line 7) and shows understanding by finishing the mother's search for words (line 9 and 11). The GP's exploration develops from missing a concern to exploring the affective aspect of the concern in the context of a family. These two extracts show that missed concerns can arise when the GP (consciously or unconsciously) orients to the topic of the routine agenda. Bringing forth the GP's attentiveness to the concern here demanded persistence from the mother.

\subsection{Termination of dialogues about concern}

The termination of the dialogue about concern was often led by the GP. This could be done in more or less marked ways. Two different practices leading to a marked termination are illustrated in the extracts below.

In a few cases, the dialogues shifted from having a psychosocial content to a biomedical one. This is illustrated in extract 7, where the GP and mother are standing by the changing table when the GP explores an earlier given cue about now being the mother of two children. Meanwhile, the GP examines the child and both the GP and the mother are looking at the child.

Extract $7(C 16)$
\begin{tabular}{|l|l|l|}
\hline 1 & M & $\begin{array}{l}\text { and I get that sometimes I feel it can be difficult (.) to (.) when you never really } \\
\text { know whether you can be with him }\end{array}$ \\
\hline 2 & GP & $\begin{array}{l}\text { but now he probably already has }(.)^{\circ} \text { can it really be true that she }{ }^{\circ}((\text { unintelligible)) } \\
\text { that she is about a: (.) } 59(.) \text { she has really taken away ((phone starts ringing)) }(\mathrm{I} \\
\text { don't believe she was only (.) } 58 \text { I don't believe that) ((unintelligible)) }\end{array}$ \\
\hline 3 & M & well I do think she is growing a lot \\
\hline
\end{tabular}

The mother tells that it troubles her that she cannot always be there for her older son when taking care of the younger child (line 1). The GP initially responds to the mother's emotional disclosure but then changes subject as the height measurement distracts. The mother cooperates with the subject change addressing the child and talking about the child's growth. The mother and the GP are multitasking, focussing on both a biomedical and psychosocial agenda and it is seen that the biomedical agenda dominates and terminates the dialogue about the concern. 
In some dialogues about concerns the GP terminated a topic by addressing the child. Such termination was effective because the parent always collaborated immediately on the termination. An example is seen in extract 8, where the GP and father are talking about the child's congenital heart defect and how a future possible operation is executed percutaneously. The camera view only shows that the child is sitting on the father's lap playing with dolls (adults' heads were out of view).

\begin{tabular}{|c|c|c|}
\hline \multicolumn{3}{|c|}{ t $8(C 2)$} \\
\hline 1 & $\mathrm{~F}$ & $\begin{array}{l}\text { e::h (.) so yes so it you know e:h (.) it it eh so it's not like (0.6) a ripping open like } \\
\text { e:h (.) eh eh the chest }\end{array}$ \\
\hline 2 & GP & $\begin{array}{l}\text { that's understandable of course tha:t that floats around in one's mind [until it's } \\
\text { over right;] }\end{array}$ \\
\hline 3 & $\mathrm{~F}$ & $\begin{array}{ll}\text { it does] it does } & \text { [yes exactly }\end{array}$ \\
\hline 4 & GP & she's $\downarrow$ thriving. (.) [that's] $\downarrow$ fine. \\
\hline 5 & & {$\left[{ }^{\circ} \downarrow \mathrm{yes}^{\circ}\right]$} \\
\hline 6 & GP & (1.0) oka:y (.)^well mm there were two Pippis? ((addressing the child)) \\
\hline 7 & $\mathrm{~F}$ & .hhye::s.h \\
\hline 8 & GP & $\uparrow o n e$ two Pippis (.) $\downarrow$ and is she in day nursery? \\
\hline 9 & $\mathrm{~F}$ & she is in day nursery up here right next to $\mathrm{x}$ in something named $\mathrm{x}$ so: \\
\hline
\end{tabular}

The father's hesitation signal, sound prolongations and small pauses show difficulty with finding the right words. The word search ends up with "ripping open the chest", a very concrete wording (line 1). The GP's response shows that the GP is aware of an underlying concern as the GP affiliates by saying that of course it floats around in one's mind (line 2). The father confirms that it floats around in his mind as preferred (line 3). The GP chooses not to explore any further but states an optimistic remark that the child is thriving and that it is fine. This is done with a falling intonation implicating closure (line 4) [29]. The father aligns responding minimally (line 5). The GP self-selects the next turn and continues with the possible pre-closer "okay" boding an upcoming subject change [23] and addresses the child with a rising intonation (line 6). Talking about an operation and then Pippi Longstockings ${ }^{2}$ is a striking subject change, but the father cooperates taking a passive role with a recipient laughter (line 6) [33] and then undertaking the active role answering the question when the GP addresses the father again (line 8 and 9).

\subsection{Additional findings}

In several cases the GPs affiliated with the parent $(n=15)$. Such affiliation also served as a device to terminate dialogues about concerns. Affiliative practices could be both lexical ("I understand that") and by mirroring the mother's prosody. In one consultation (C24), the GP makes a declarative assessment referring to the HADS score: "and this looks really good (.) there is nothing really concerning". The mother confirms as sequentially preferred with a no. However, the no is prolonged and subsequently the mother elaborates that sometimes her "hair is on fire" because she has three small children. The GP replies affiliating and non-exploring: "yes yes agree hehe".

\footnotetext{
${ }^{2}$ The child is playing with a Pippi Longstocking doll. Pippi Longstocking is a character from a Swedish childrens' book.
} 
Concerns that seemed to be given brief attention were sometimes brought up later in the visit. An example of this was when a mother several times hints about her concern as to whether the child's sleeping pattern was normal. The GP did not engage in exploration twice, but at the end of the consultation the GP said: "so, about the daily rhythm-..." However, raising the concern again did not necessarily mean exploration; instead normalisation could be observed (C10). Another way of handling a concern was suggesting booking a new appointment or referral to other specialists.

\section{Discussion and conclusion}

\subsection{Discussion}

Four combinations of question design and exploration were identified (table 1). This discussion focuses upon the findings regarding non-optimised questions and termination practices.

Three quarters of GPs' preceding questions had non-optimised designs, where grammar and content offered a window for the parent to share potential concerns. Although GPs' question designs were attentive to a concern, they did not necessarily lead to exploration of that concern. Literature has focussed on helping health professionals to prompt patients' disclosure of concerns [13-16]. Our study shows that bringing concerns out into the open does not necessarily lead to subsequent exploration: the GPs' initially attentive practices did not ensure that concerns were actually addressed.

GPs could change from non-exploratory to exploratory practice within the same consultation. This finding indicates that the GPs vary both in their overall sensitivity and in their ability and/or willingness to identify subtle cues from parents, even within a single consultation. To our knowledge little literature exists on why these shifts in GPs' conversational practice take place. Our findings suggest that the parents' persistence can trigger the GPs' awareness. Since parents have different conversational styles and varying resistance to expression of emotional concerns during a consultation $[12,18]$ this may lead to the concerns of less insistent parents being left unexplored.

Existing literature has focused on physicians' identification of and subsequent responses to patients' concerns [24, 34]. However, to our knowledge, the literature on GPs' termination practices in concern talk is sparse. A study based in adult settings has shown that attendance to physical aspects can be a terminator [35]. Our study confirms this finding. We also identified another terminator: addressing the child directly. In these cases, the parent shifts participant role from an addressee to a ratified listener [36]. In this new role, the parent is expected to listen but not to participate to the same degree as the addressee, and consequently the GP creates a window to terminate effectively. Such an abrupt termination in therapeutic encounters with two adult patients would not pass by unnoticed, but in the setting of preventive CHA, shifting participant roles appeared unproblematic. There are several strong mechanisms making any questioning of the physicians' behaviour difficult including a fundamental acceptance of the interactional asymmetry embedded in the physicians' task [37], parental uncertainty about the purpose of the preventive $\mathrm{CHA}$ and the role of their concerns $[12,38]$. All these factors together facilitate strong parental cooperation. This calls for an increased awareness among GPs about their exploration- and termination practices.

There is limited knowledge of the structure of dialogues about parental concerns in preventive child health assessments. Mellblom et al. have investigated the sequential context around emotional concerns in follow-up visits with adolescents with childhood cancer [39]. Our study differs because it tries to capture concerns in preventive visits where there is no pre-defined concern or problem [40]. This puts extra demands on both GP and parent to bring concerns into the open. Furthermore, to our knowledge the present study is the first to investigate the sequential context of concerns in terms of the 
GPs' preceding question and potential subsequent exploration. Surprisingly, we found that GPs' initial attentive practice did not necessarily lead to subsequent exploration - some concerns were still left hanging. This points to the need for future studies investigating the mechanisms determining GPs' exploration after their solicitation of concerns.

The video-recorded consultations offered a unique insight into how dialogues about concerns

take form in preventive consultations. For video-recorded social interaction, CA is a rigorous analytical approach to elucidate conversational patterns and to bring new understanding of an interactional phenomenon [41]. In this study, we identified patterns of management of concerns, but we do not provide knowledge on the underlying mechanisms. Future research combining CA with video stimulation interviews could provide access to the conceptualisations, aims and concerns which stimulate GPs' exploration and could potentially create a more nuanced foundation for communication training [42].

There were some limitations of our study: A modest sample size and varying access to non-verbal behaviour due to limited camera view. Furthermore, the GPs were selected through convenience sampling. It is likely that the GPs had a greater than average interest in psychosocial matters, differentiating them from the majority of GPs. The GPs also decided which families to recruit to the study with the aim of representing examinations between the ages of 5 weeks to two years. This method of purposive sampling could therefore have led to selection bias at family level.

\subsection{Conclusion}

Preventive CHAs aim to identify early signs and symptoms which might be associated with later health problems. Professionals, who carry out these assessments obtain their information about the child from their own and the parent's observations. Professionals' sensitivity to parental concern is a precondition to effective preventive assessments but exploration is inevitably constrained in routine consultations. Although GPs exhibit attentive questioning practices, many disclosed emotional concerns are left unattended. Nevertheless, GPs sometimes employed an exploratory approach later within the same consultation. Parents cooperate with most attempts that GPs make to terminate discussion about concerns in the setting of a preventive child health assessment, so many of these concerns remain unexplored.

\subsection{Practice implications}

Preventive CHAs offer an opportunity for parents to raise concerns about their children's development. These assessments by nature have a "healthy child agenda" and professionals' sensitivity to parental concerns is crucial to the success of this preventive work. Improved professional understanding of the conversational mechanisms through which concerns are examined or sidelined should allow clinicians to maximise the effectiveness of their preventive consultations with children, and potentially with other patient groups.

\section{Funding}

This study was supported by Lundbeckfonden and Trygfonden.

\section{Conflict of interest}

None.

\section{References}


[1] P. Wilson, R. Wood, K. Lykke, A. Hauskov Graungaard, R.K. Ertmann, M.K. Andersen, O.R. Haavet, P. Lagerlov, E. Abildsnes, M.P. Dahli, M. Makela, A. Varinen, M. Hietanen, International variation in programmes for assessment of children's neurodevelopment in the community: Understanding disparate approaches to evaluation of motor, social, emotional, behavioural and cognitive function, Scandinavian Journal of Public Health. 2018;46:805-816. https://doi.org/10.1177/1403494818772211

[2] Sundhedstyrelsen, Vejledning om forebyggende sundhedsydelser til børn og unge 2011. [Recommendations on preventive child health services for children and youth 2011] https://www.sst.dk/ /media/6770049FEA8442DA8409E5127ABCAD24.ashx (Accessed December 2018).

[3] G. Sondergaard, S. Biering-Sorensen, S.I. Michelsen, O. Schnor, A.M. Andersen, Non-participation in preventive child health examinations at the general practitioner in Denmark: a register-based study, Scand J Prim Health Care 2008;26:5-11. https://doi.org/10.1080/02813430801940877

[4] M. Richards, J. Mossey, D.L. Robins, Parents' Concerns as They Relate to Their Child's Development and Later Diagnosis of Autism Spectrum Disorder, JDBP. 2016;37:532-40.

https://doi.org/10.1097/DBP.0000000000000339

[5] R.C. Sheldrick, E.N. Neger, E.C. Perrin, Concerns about development, behavior, and learning among parents seeking pediatric care, JDBP. 2012;33:156-160. https://doi.org/10.1097/DBP.0b013e3182420f4a

[6] K. Sayal, E. Taylor, Detection of child mental health disorders by general practitioners, Br J Gen Pract. 2004;54:348-52.

[7] F.P. Glascoe, Parents' concerns about children's development: prescreening technique or screening test?, Pediatrics. 1997;99:522-8. https://doi.org/10.1542/peds.99.4.522

[8] S.A. Reijneveld, G. de Meer, C.H. Wiefferink, M.R. Crone, Parents' concerns about children are highly prevalent but often not confirmed by child doctors and nurses, BMC Public Health. 2008;8:124.

https://doi.org/10.1186/1471-2458-8-124

[9] Y.P. Wu, B.M. Messner, M.C. Roberts, Children's psychosocial problems presenting in a family medicine practice, Journal of Clinical Psychology in Medical Settings. 2010;17:203-10. https://doi.org/10.1007/s10880$\underline{010-9195-2}$

[10] K.A. Burklow, L.M. Vaughn, K.S. Valerius, J.R. Schultz, Parental expectations regarding discussions on psychosocial topics during pediatric office visits, Clin Pediatr (Phila). 2011;40;555-62.

https://doi.org/10.1177/000992280104001004

[11] S.M. Horwitz, P.J. Leaf, J.M. Leventhal, Identification of psychosocial problems in pediatric primary care: do family attitudes make a difference?, Arch of Pediatr Adolesc Medicine. 1998;152:367-71.

https://doi.org/10.1001/archpedi.152.4.367 
[12] K. Sayal, V. Tischler, C. Coope, S. Robotham, M. Ashworth, C. Day, A. Tylee, E. Simonoff, Parental helpseeking in primary care for child and adolescent mental health concerns: qualitative study, The British Journal of Psychiatry. 2010;197:476-81. https://doi.org/10.1192/bjp.bp.110.081448

[13] L.G. Hayutin, B. Reed-Knight, R.L. Blount, J. Lewis, M.L. McCormick, Increasing parent-pediatrician communication about children's psychosocial problems, J Pediatr Psychol. 2009;34:1155-64. https://doi.org/10.1093/ipepsy/isp012

[14] L. Sices, D. Drotar, A. Keilman, H.L. Kirchner, D. Roberts, T. Stancin, Communication about child development during well-child visits: impact of parents' evaluation of developmental status screener with or without an informational video, Pediatrics. 2008;122(5):1091-9. https://doi.org/10.1542/peds.2008-1773

[15] J.W. Finney, C.J. Brophy, P.C. Friman, A.S. Golden, G.S. Richman, A.F. Ross, Promoting parent-provider interaction during young children's health-supervision visits, J Appl Behav Anal. 1990;23:207-13.

https://doi.org/10.1901/jaba.1990.23-207

[16] E.G. Triggs, E.C. Perrin, Listening carefully. Improving communication about behavior and development. Recognizing parental concerns, Clin Pediatr (Phila). 1989:28:185-92.

https://doi.org/10.1177\%2F000992288902800407

[17] L.S. Wissow, S. Larson, J. Anderson, E. Hadjiisky, Pediatric residents' responses that discourage discussion of psychosocial problems in primary care, Pediatrics. 2005;115:1569-78. https://doi.org/10.1542/peds.2004$\underline{1535}$

[18] L. Krippeit, F. Belzer, H. Martens-Le Bouar, V. Mall, M. Barth, Communicating psychosocial problems in German well-child visits. What facilitates, what impedes pediatric exploration? A qualitative study, Patient Educ Couns. 2014;97:188-94. https://doi.org/10.1016/i.pec.2014.07.032

[19] J. Heritage, M.-L. Sorjonen, Constituting and maintaining activities across sequences: "And-prefacing" as a feature of question design, Lang Soc. 1994;23:1-29. https://doi.org/10.1017/S0047404500017656

[20] A.S. Zigmond, R.P. Snaith, The hospital anxiety and depression scale, Acta Psychiatr Scand. 1983;67:361-70. https://doi.org/10.1111/j.1600-0447.1983.tb09716.x

[21] Y. Hatakenaka, E. Fernell, M. Sakaguchi, H. Ninomiya, I. Fukunaga, C. Gillberg, ESSENCE-Q - a first clinical validation study of a new screening questionnaire for young children with suspected neurodevelopmental problems in south Japan, Neuropsychiatric Disease and Treatment. 2016;12;1739-46.

https://doi.org/10.2147/NDT.S108411

[22] J. Heritage, Garfinkel and Ethnomethodology, Polity Press, Cambridge, 1984.

[23] E.A. Schegloff, H. Sacks, Opening up closings, Semiotica. 1973;8:289-327. https://doi.org/10.1515/semi.1979.8.4.289

[24] C. Zimmermann, L. Del Piccolo, A. Finset, Cues and concerns by patients in medical consultations: a literature review, Psychological Bull. 2007;33:438-63. https://doi.org/10.1037/0033-2909.133.3.438 
[25] J. Heritage, S., Clayman, Talk in action interactions, identities, and institutions, Wiley-Blackwell, Malden, 2010. https://doi.org/10.1002/9781444318135

[26] G. Jefferson, Glossary of transcript symbols with an introduction, Pragmat. Beyond New Ser. 2004;125:1334. https://doi.org/10.1075/pbns.125.02jef

[27] Hutchby, "Active Listening": Formulations and the Elicitation of Feelings-Talk in Child Counselling, Res. Lan Soc. Interact, 2005;38:303-329. https://doi.org/10.1207/s15327973rlsi38034

[28] G. Jefferson, On the organization of laughter in talk about troubles, in: J.M. Atkinson, J. Heritage (Eds.), Structures of social action: Studies in conversation analysis, Cambridge University Press, Cambridge, 1984; pp. 346-369. https://doi.org/10.1017/CBO9780511665868

[29] G. Jefferson, On the sequential organization of troubles-talk in ordinary conversation, Soc. Probl. 1988;35:418-441. https://doi.org/10.2307/800595

[30] J. Heritage, A change-of-state token and aspects of its sequential placement. In J. Atkinson and J. Heritage (Eds.), Structures of Social Action: Studies in Conversation Analysis, Cambridge: Cambridge University Press. 1984, pp. 299-345. https://doi.org/10.1017/CBO9780511665868.020

[31] A. Pomerantz, 'Agreeing and Disagreeing with Assessments: Some Features of Preferred/Dispreferred Turn Shapes', In J. Atkinson and J. Heritage (eds), Structures of Social Action: Studies in Conversation Analysis, Cambridge: Cambridge University Press. 1984, pp. 57-101. https://doi.org/10.1017/S0022226700011464

[32] T. Stivers, J. Heritage, Breaking the sequential mold: Answering 'more than the question' during comprehensive history taking, Text - Interdisciplinary Journal for the Study of Discourse. 2001;21:151-185. https://doi.org/10.1515/text.1.21.1-2.151

[33] K. Ikeda, D. Bysouth, Laughter and Turn Taking: Warranting Next Speakership in Multiparti Interactions, in P. Gleen, E. Holt (Eds.), Studies of Laughter in Interaction, Bloomsbury Publishing, London, 2013, pp. 39-64.

[34] A. Finset, 'I am worried, doctor!' Emotions in the doctor-patient relationship, Patient Educ Couns. 2012;88:359-363. https://doi.org/10.1016/i.pec.2012.06.022

[35] A.L. Suchman, K. Markakis, H.B. Beckman, R. Frankel, A model of empathic communication in the medical interview, J Amer Med Assoc. 1997;277:678-82. https://doi.org/10.1001/jama.1997.03540320082047

[36] E. Goffman, Replies and Responses, Language in Society. 1976;5:257-313. https://doi.org/10.1017/s0047404500007156

[37] A. Pilnick, R. Dingwall, On the remarkable persistence of asymmetry in doctor/patient interaction: a critical review, Social science \& medicine, 2011;72:1374-82. https://doi.org/10.1016/j.socscimed.2011.02.033

[38] K.M. Michelsen SI, Flachs EM, Søndergaard G, Biering-Sørensen S, Madsen M, Andersen AMN, Evaluering af de forebyggende børneundersøgelser i Almen Praksis 2007 [Evaluation of the preventive child health 
assessments in general practice 2007], Sundhedsstyrelsen, Statens Institut for Folkesundhed, Syddansk Universitet, 2007.

[39] A. V. Mellblom, L. Korsvold, E. Ruud, H. C. Lie, J. H. Loge, A. Finset, Sequences of talk about emotional concerns in follow-up consultations with adolescent childhood cancer survivors, Patient Educ Couns.

2016;99:77-84. https://doi.org/10.1016/j.pec.2015.07.021

[40] J. Heritage, J.D. Robinson, Accounting for the visit: giving reasons for seeking medical care, in: D.W. Maynard, J. Heritage (Eds.), Communication in Medical Care: Interaction between Primary Care Physicians and Patients, Cambridge University Press, Cambridge, 2006, pp. 48-85.

https://doi.org/10.1017/CBO9780511607172.005

[41] M. Pino, R. Parry, Talking about death and dying: Findings and insights from five conversation analytic studies, Patient Educ Couns. 2019;102:185-187. https://doi.org/10.1016/j.pec.2019.01.011

[42] A. Pomerantz, Using participants' video stimulated comments to complement analyses of interactional practices, in H. Molder \& J. Potter (Eds.), Conversation and cognition, Cambridge University press, Cambridge, 2005, pp. 93-113. https://doi.org/10.1017/CB09780511489990.005 